\title{
Promoting Resilience in Stress Management
}

National Cancer Institute

\section{Source}

National Cancer Institute. Promoting Resilience in Stress Management. NCI Thesaurus. Code C153554.

A resilience-building intervention program for adolescents and young adults with serious illness. It focuses of 4 disease-non-specific skills: stress management, goal-setting and problem-solving, positive re-appraisals of stressors, and meaning-making or benefitfinding. 